\title{
Awareness, knowledge, attitude and practices regarding human papilloma virus among female students at the University of Namibia
}

\author{
Hans Justus Amukugo, Blessing Rufaro Rungayi, Abel Karera* \\ School of Nursing, Faculty of Health Sciences, University of Namibia, Windhoek, Namibia
}

Received: June 22, 2018

DOI: $10.5430 /$ ijh.v4n2p51

\author{
Accepted: August 16, 2018 \\ Online Published: August 28, 2018 \\ URL: https://doi.org/10.5430/ijh.v4n2p51
}

\begin{abstract}
Purpose: The high prevalence of human papilloma virus (HPV) infection and its association with cervical cancer (as one of the leading causes of death in Namibia) makes it important to determine the level of understanding as well as beliefs of the public regarding HPV, especially that of young university female students. The purpose of the study was to determine awareness, knowledge, attitude and practices regarding HPV, among female students at the University of Namibia.

Methods: A quantitative cross sectional research design was adopted using a convenient sample of 126 female students from the 534 females at the health sciences faculty, University of Namibia, Main Campus. Data was collected using a modified, adopted self-administered questionnaire and analysed using Microsoft Excel 2013.

Results: The majority of participants were below 25 years (79.1\%), single (91.7\%) and nursing students (93.3\%). HPV awareness was generally high with the majority aware of HPV infection (71\%), cervical cancer $(94.2 \%)$, genital warts (90\%) and HPV vaccine (54.2\%). Only $40 \%$ knew that HPV could be transmitted through skin to skin contact and only $9.2 \%$ knew that HPV was not associated with herpes. Attitude towards HPV was positive, $55 \%$ believed they were at risk of HPV and $82 \%$ were willing to receive the HPV vaccine. Practices regarding HPV were poor, $68 \%$ were sexually active, $40 \%$ reported using condoms sometimes, $7 \%$ never used condoms at all and $75 \%$ had never had a Pap smear test done.

Conclusions: Level of awareness and knowledge of HPV, its related diseases and vaccines was moderate to high, attitude was generally positive whilst practice was poor among female students at the health sciences faculty, University of Namibia. Students need to be encouraged to engage in safe sexual practice to prevent and reduce risk of HPV infection.
\end{abstract}

Key Words: Knowledge, Attitude, Practices, Human papilloma virus, Students

\section{INTRODUCTION}

Human papilloma virus (HPV) is the most common viral infection of the reproductive tract that is sexually transmitted through skin to skin contact including penetrative and nonpenetrative means such as open mouth kissing and oral sex..$^{[1]}$ There are numerous strains of HPV that produce different effects on exposure to cells of the throat, tongue, vagina, cervix, valve, anus, and penis. ${ }^{[2]}$ It is estimated that most sexually active women and men will be infected with HPV at some point in their lives and some maybe repeatedly infected. ${ }^{[3]}$ In addition, most of the HPV infections disappear on their own without any physical symptoms whilst some

\footnotetext{
*Correspondence: Abel Karera; Email: akarera@unam.na; Address: Faculty of Health Sciences, School of Nursing Main Campus, Private Bag 13301, Windhoek, Namibia.
} 
persist and progress to cause warts and cancers, in particular cervical cancer. ${ }^{[2]}$ Cervical cancer is the most common HPV related disease with approximately $93 \%$ of cervical cancers having been reported to contain some form of HPV DNA. ${ }^{[4]}$ Cervical cancer is the second most common cancer in women living in less developed regions with an estimated 445,000 new cases in 2012 accounting for $84 \%$ of new cases worldwide. ${ }^{[3]}$ It has been recognised that the burden for cervical cancer is higher in developing countries compared to developed countries. ${ }^{[5]}$ The link between HPV and cervical cancer provides an opportunity for reduction of cervical cancer incidence through prevention of new HPV infections. This can be achieved through practicing safe sex, having mutually monogamous relationships and early screening for both males and females. ${ }^{[2]}$

The high prevalence of HPV and its association with cervical cancer (one of the leading causes of death), makes it important to determine the level of understanding as well as beliefs of the public regarding HPV, especially that of young university female students. One previous study revealed that young college females between the ages of 18-24 years were at risk of being infected with HPV. ${ }^{[6]}$ Another study in Nigeria reported low levels of awareness of HPV infection (17.7\%) and HPV vaccine (14.4\%) among university students. ${ }^{[7]}$ It becomes therefore, important to determine the knowledge of this population regarding HPV as they stand a better chance at influencing behaviour in the community. Namibia is a sub-Saharan African country that has an estimated total population of over 2.4 million. ${ }^{[8]}$ Of the 2.4 million people, 813,157 are women aged between 15 to 44 years who are at risk of getting cervical cancer. About 132 new cervical cancer cases are diagnosed annually in Namibia and 59 of these women die annually. Contributing factors to cancer of the cervix in Namibia are: smoking in women (11.7\%), total fertility rate $(3.6 \%)$, hormonal contraceptive use (34\%) and high HIV prevalence (13.3\%). ${ }^{[9]}$ In a study done in 1988 it was found out that Namibia had one of the highest cervical intraepithelial neoplasia (CIN) and human papilloma virus infection prevalence in the world. ${ }^{[10]}$

In a report by the Ministry of Health on the needs assessment titled; screening for reproductive system cancers in Namibia, it was concluded that knowledge of the community pertaining to specific information on reproductive cancers appeared to be low. The report also indicated that there was little community education and awareness campaigns on reproductive cancers and that there was still a lot of myths existing in the community. It went on to highlight that factors influencing people from accessing screening services and seeking help in detecting cancers early were due to lack of information, ignorance, cultural beliefs pertaining to cancers, lack of in- formation on screening services available and other health system barriers. ${ }^{[11]}$ Knowledge and attitude are important factors that affect behaviour of an individual. Low levels of knowledge and negative attitude of the public may adversely affect behaviour towards HPV prevention and inadvertently increase the burden of HPV in Namibia. The aim of the study was to determine the level of awareness, knowledge, attitudes and practices regarding Human papilloma virus among female students at University of Namibia (UNAM), main campus.

\section{METHODS}

A quantitative, cross sectional survey design was used to collect data in September 2016. The sample was obtained from the health sciences faculty, which had a total of 534 female students registered for the year 2016. The sample size was 126, calculated using Epi info 7 statCalc for descriptive studies. A non-probability convenience sampling method was utilized to recruit participants.

A questionnaire designed with question adopted and modified from previous similar studies ${ }^{[7,12-14]}$ was used to collect data. It consisted of five sections containing grouped questions on demographics, awareness, knowledge, attitude and practice. A combination of close ended and Likert scale questions were used in the questionnaire. Data was analysed using Microsoft Excel 2013.

Ethical approval to conduct the research was obtained from the UNAM School of Nursing and Ministry of Health and Social Services Namibia. Informed consent was utilised and respondents voluntarily participated in study. The principle of respect, justice, autonomy and beneficence were observed.

\section{RESUltS}

A total of 126 questionnaires were distributed and 120 were returned (95.2\% response rate), the majority (93.3\%) being from Bachelor of Nursing Science students. Most participants $(91.7 \%)$ were single whilst $(8.3 \%)$ were married. Participants were in their first (18.3\%), second (25\%), third (41.7\%) and fourth (15\%) year of study. The age of the participants ranged from $16-40$ with the majority $(79.1 \%)$ being below 25 years of age.

\subsection{Awareness of HPV}

Most of the participants were aware of what HPV is (70.8\%), and knew what cervical cancer and Pap smear were (94.2\%). Health care providers were reported by the majority $(67 \%)$ as the source of information on HPV as shown in Table 1. 


\subsection{Knowledge on HPV and cervical cancer}

In this section, participants were given twelve statements and asked to indicate whether each statement was true or false. For seven $(58.3 \%)$ of the questions, less than $50 \%$ of the participants managed to give the correct response. Only three $(25 \%)$ questions were most frequently (> 75\%) correctly indicated as either true or false. The responses on all the statements regarding knowledge are shown in Table 2.

\subsection{Attitudes towards HPV}

Attitudes are moulded around an individuals' belief about a phenomenon. Participants were asked to indicate whether they agree or disagree with ten statements related to attitude regarding HPV. The majority of the participants $(81.7 \%)$, agreed that contracting HPV is serious and life threatening whilst only $45.8 \%$ believed that they were not at risk of HPV infection. On willingness to get the HPV vaccine, $81.7 \%$ agreed to get this vaccine. Almost all the participants (95\%) agreed and indicated that they intent to get more education on HPV and its vaccine from experts. The summary of results regarding participants' attitude are presented in Table 3.

\subsection{Practice regarding HPV}

Sexual activities of the participants, linked to HPV, were assessed by a series of questions as summarized in Table 4. The majority $(68.3 \%)$ reported being sexually active and of these, $19.5 \%$ had two or more sexual partners whilst only $51 \%$ reported using a condom all the time during sexual activities. Only $25 \%$ of the participants indicated having had a pap smear done.

Table 1. Awareness of HPV

\begin{tabular}{|c|c|c|c|}
\hline Question & Responses & Frequency $(n=120)$ & Percentages (\%) \\
\hline \multirow{2}{*}{ Have you ever heard of human papilloma virus? } & Yes & 85 & 70.8 \\
\hline & No & 35 & 29.2 \\
\hline \multirow{2}{*}{ Have you ever heard of cancer of the cervix } & Yes & 113 & 94.2 \\
\hline & No & 7 & 5.8 \\
\hline \multirow{2}{*}{ Have you ever heard of genital (growths of the skin) } & Yes & 108 & 90 \\
\hline & No & 12 & 10 \\
\hline \multirow{2}{*}{ Have you ever heard of a pap smear test } & Yes & 113 & 94.2 \\
\hline & No & 7 & 5.8 \\
\hline \multirow{2}{*}{ Have you ever heard of HPV vaccine } & Yes & 65 & 54.2 \\
\hline & No & 55 & 45.8 \\
\hline \multirow{3}{*}{$\begin{array}{l}\text { Source of information on HPV }(n=120) \\
\text { (some participants indicated twice) }\end{array}$} & Media & 39 & 29 \\
\hline & Family members or friends & 6 & 4 \\
\hline & Health care providers & 91 & 67 \\
\hline
\end{tabular}

Table 2. Knowledge on HPV and Cervical cancer

\begin{tabular}{lll}
\hline Statement & Correct response & Percent correct (\%) \\
\hline HPV causes herpes & False & 9.2 \\
Genital warts are caused by HPV & True & 61.7 \\
HPV can cause cancer of the cervix & True & 81 \\
If a woman's pap smear is normal, she does not have HPV & False & 40.5 \\
Most people with HPV have no visible signs and symptoms & True & 55 \\
HPV is a sexually transmitted infection & True & 77 \\
HPV can be transmitted through skin to skin contact & True & 40 \\
A vaccine exists to prevent cervical cancer & True & 40.5 \\
A vaccine exists to prevent genital warts & True & 24 \\
A vaccine exists to prevent HPV infection & False & 37 \\
The vaccine is available in Namibia & True & 45 \\
Using a condom can provide partial protection & True & 80 \\
\hline
\end{tabular}


Table 3. Attitudes towards HPV and cervical cancer

\begin{tabular}{|c|c|c|c|}
\hline Statement & Responses & Frequency $(\mathrm{N}=120)$ & Percentage (\%) \\
\hline \multirow{3}{*}{ I am at risk of HPV infection } & Agree & 55 & 45.8 \\
\hline & Disagree & 45 & 37.5 \\
\hline & Uncertain & 20 & 16.7 \\
\hline \multirow{3}{*}{ I am at risk of cervical cancer } & Agree & 77 & 64.1 \\
\hline & Disagree & 32 & 26.7 \\
\hline & Uncertain & 11 & 9.2 \\
\hline \multirow{3}{*}{ I worry about having genital warts } & Agree & 63 & 52.5 \\
\hline & Disagree & 45 & 37.5 \\
\hline & Uncertain & 12 & 10 \\
\hline \multirow{3}{*}{ I am at risk of genital HPV infection } & Agree & 50 & 41.7 \\
\hline & Disagree & 52 & 43.3 \\
\hline & Uncertain & 18 & 15 \\
\hline \multirow{3}{*}{$\begin{array}{l}\text { I believe that contracting HPV is serious and life } \\
\text { threatening }\end{array}$} & Agree & 98 & 81.7 \\
\hline & Disagree & 12 & 10 \\
\hline & Uncertain & 10 & 8.3 \\
\hline \multirow{3}{*}{$\begin{array}{l}\text { HPV vaccine to be given to girls before they } \\
\text { become sexually active }\end{array}$} & Agree & 89 & 74.2 \\
\hline & Disagree & 20 & 16.7 \\
\hline & Uncertain & 11 & 9.1 \\
\hline \multirow{3}{*}{$\begin{array}{l}\text { HPV vaccine to be given only to sexually active } \\
\text { females }\end{array}$} & Agree & 35 & 29.2 \\
\hline & Disagree & 76 & 63.3 \\
\hline & Uncertain & 9 & 7.5 \\
\hline \multirow{3}{*}{$\begin{array}{l}\text { HPV vaccine should be given to people with } \\
\text { multiple sexual partners }\end{array}$} & Agree & 24 & 20 \\
\hline & Disagree & 84 & 70 \\
\hline & Uncertain & 12 & 10 \\
\hline \multirow{3}{*}{ I am willing to get the vaccine } & Agree & 98 & 81.7 \\
\hline & Disagree & 15 & 12.5 \\
\hline & Uncertain & 7 & 5.8 \\
\hline \multirow{3}{*}{$\begin{array}{l}\text { I intend to get more education on HPV and vaccine } \\
\text { from experts }\end{array}$} & Agree & 114 & 95 \\
\hline & Disagree & 3 & 2.5 \\
\hline & Uncertain & 3 & 2.5 \\
\hline
\end{tabular}

Table 4. Practice regarding HPV

\begin{tabular}{|c|c|c|c|}
\hline Question & Responses & Frequency & Percentage (\%) \\
\hline \multirow{2}{*}{ Are you sexually active $(n=120)$} & Yes & 82 & 68.3 \\
\hline & No & 38 & 31.7 \\
\hline \multirow{3}{*}{$\begin{array}{l}\text { How many sexual partners have you had in the } \\
\text { past } 12 \text { months }(n=82)\end{array}$} & 1 & 66 & 80.5 \\
\hline & 2 & 10 & 12.2 \\
\hline & $3+$ & 6 & 7.3 \\
\hline \multirow{3}{*}{ How often do you use a condom $(n=82)$} & All the time & 42 & 51 \\
\hline & sometimes & 33 & 40.2 \\
\hline & Not at all & 7 & 9 \\
\hline \multirow{2}{*}{ Have you ever had a pap smear done $(n=120)$} & Yes & 30 & 25 \\
\hline & no & 90 & 75 \\
\hline \multirow{2}{*}{ Do you smoke $(n=120)$} & Yes & 1 & 1 \\
\hline & No & 119 & 99 \\
\hline If yes how many times $(n=1)$ & Once in two weeks & & \\
\hline \multirow{2}{*}{$\begin{array}{l}\text { Did you ever give birth or been pregnant before } \\
(\mathrm{n}=120)\end{array}$} & Yes & 25 & 21 \\
\hline & No & 95 & 79 \\
\hline
\end{tabular}




\section{Discussion}

Most of the participants in this study were young, the majority, and $79.1 \%$ being less than 25 years of age, and single, $91.7 \%$. This is the normal university going age for most school leavers and most of them will be single at this age. This is consistent with other similar studies that reported the same age findings ${ }^{[7,12,15]}$ among university students. This age range is considered to be at high risk of contracting HPV because most individuals will be sexually active. ${ }^{[6]}$ Participants in this study were selected across the four years of study to ensure full representation of the whole spectrum of female students at the Faculty of health Sciences, University of Namibia.

\subsection{Awareness of HPV}

Participants in this study showed a relatively moderate to high level of awareness regarding awareness to HPV. The minimum score was $54.2 \%$ and the maximum score was $94.2 \%$ with an average of $80.6 \%$ correct responses. Students within the health science faculty are exposed to information on sexual health as they go through their theoretical and clinical classes. This can be the reason for the high level of awareness displayed by the participants in this study. The majority of students reported that they have heard about HPV infection (70.8\%) and HPV vaccine (54.2\%), a trend higher than reported in similar studies. A study at the University of Lagos, Nigeria, among non-medical students, reported a low level of HPV (17.7\%) or HPV vaccine (14.4\%) awareness among the students. ${ }^{[7]}$ The field of study has been reported to contribute to awareness and knowledge on HPV and HPV vaccine among university students. A study done in Pakistan, on a combined sample of health sciences and non-health sciences students, reported an above average level of awareness on HPV with strong association between level of awareness and the field of study. ${ }^{[16]}$ Almost all the participants in this study were aware of cervical cancer and Pap smear test, reflective of the high level of awareness of health sciences students with matters related to health. This is consistent with another similar study in South Africa were $90 \%$ and $70 \%$ were aware of cervical cancer and Pap smear respectively. ${ }^{[12]}$ In contrast, non-health sciences students reported just above average level of awareness $(54.2 \%)$ in Nigeria. ${ }^{[7]}$

Awareness of HPV vaccine was above average (54.2\%), compared to the $90.9 \%$ who were aware of the vaccine as reported in one study done among medical students in India. ${ }^{[17]}$ The difference between the results of the two studies is probably because in Namibia the vaccine has not been introduced on a commercial level apart from a few private medical practices, hospitals and pharmacies, therefore the participants have not been fully exposed to it in clinical practice.
Source of information regarding HPV and HPV vaccine was mainly from healthcare providers as the participants were students. This is in contrast to a study on university students in South Africa were the majority (58\%) reported media as the main source of information. ${ }^{[12]}$ This trend was also noted in Thailand were the majority $(70.8 \%)$ cited media as the main source of information. ${ }^{[18]}$

\subsection{Knowledge on HPV and cervical cancer}

Specific knowledge on HPV and cervical cancer was surprisingly low to average among students in this study. The minimum percentage of correct responses was $9.2 \%$ with a maximum of $81 \%$ on individual question. On average, $49.2 \%$ got the questions correct in this study, a figure relatively low considering the students were from health sciences faculty. This is in contrast to a study done in Malaysia among medical students were $90 \%$ were reported to have a high level of knowledge. ${ }^{[19]}$ Compared to non-health sciences student, where $90 \%$ showed low levels of knowledge,${ }^{[7]}$ participants in this study showed a better level of knowledge on HPV and cervical cancer. Of note was the question where participants were asked to indicate whether it's true that HPV causes herpes which appeared most challenging, with only $9.2 \%$ managing to get it correct. This could be due to confusion between HPV and sexually transmitted diseases, however, this trend was also reflected in a similar study in South Africa. ${ }^{[12]}$ The majority of participants (81\%), could identify the link between HPV and cervical cancer which is comparable to findings in a similar study among nurses in Thailand, ${ }^{[18]}$ where $(81.8 \%)$ positively identified HPV as a causal factor for cervical cancer and medical students in India, ${ }^{[17]}$ where $94.3 \%$ said the same.

Knowledge of the mode of transmission of diseases is very important especially among health care workers as this provides the bases for preventative advice during interaction with patients. Whilst the majority of participants agreed that HPV is sexually transmitted, a few (40\%) were able to identify skin to skin contact (non-sexual transmission) as a mode of transmission of the virus. This was not surprising as very low levels of knowledge (7.3\%) regarding this mode of transmission have been reported in another previous study. ${ }^{[20]}$

Participants in this study had limited knowledge on the existence of a vaccine to prevent cervical cancer or the availability of this vaccine to the public in Namibia. Only $40.5 \%$ and $45 \%$ indicated that cervical cancer vaccine exists and that it is available in Namibia respectively. This can also be explained by the relatively recently exposure of the Namibia population to the vaccine making knowledge about its existence and access uncommon to the majority of the population 
including healthcare students. This trend however was not peculiar to this study as similar studies in South Africa ${ }^{[12]}$ and Nigeria ${ }^{[20]}$ have reported the same trend.

\subsection{Attitudes towards HPV and cervical cancer}

There was generally a positive attitude (average $67 \%$ positive responses) towards HPV and cervical cancer in this study. Whilst the majority of the participants acknowledged that contracting HPV infection was a serious infection, the same could not be said regarding appreciation of risk. The age of the participants and their sexually active status places them at a risk for HPV and HPV related diseases such cervical cancer. However, only $45.8 \%$ and $52.5 \%$ indicated that they were at risk of HPV and genital warts infection respectively, figures which are inconsistent with those sexually active (68.2\%) in the sample. The appreciation of risk is considerably high when compared to figures reported in Nigeria ${ }^{[7]}$ where only $6.25 \%$ and $6.9 \%$ agreed that they could be at risk of HPV infection and cervical cancer respectively.

With regard to taking part in vaccination programmes, the majority ( $81.7 \%)$, indicated their willingness to be vaccinated against HPV, which was very positive and can be attributed to the majority belief that contracting HPV is serious and life threatening. A similar trend was also seen among nursing students in Turkey, ${ }^{[15]}$ where $66.3 \%$ highlighted willingness to be vaccinated for HPV. This belief, in turn effected positive attitude towards engagement in preventative activities. The positive belief regarding preventative measures was also reflected in issues regarding vaccination of girls before and after becoming sexually active. Most of the participants were of the belief that HPV vaccine should be given at any stage and to all girls in order to prevent HPV infection. This was in contrary to an earlier study, ${ }^{[13]}$ where only $48 \%$ of the participant's highlighted intention to get the HPV vaccine. The participants of this study additionally acknowledged their limited knowledge regarding HPV infection and HPV vaccine as indicated by their willingness to get more information from experts regarding to two aspects.

\subsection{Practice regarding HPV}

An individual's knowledge and attitude towards a phenomenon can subconsciously or consciously affect their behaviour towards such a phenomenon. In this study, practice relating to activities associated with HPV infection was as- sessed. Activities that an individual engage in can either place them at risk or reduced risk of HPV infection. Most the participants were sexually active in this study a trend consistent with other studies conducted at universities or tertiary institution. ${ }^{[12,19]}$ This would require the majority to adopt safe practice to minimise chances of HPV infection, however, only $51 \%$ of those sexually active reported using a condom every time they engage in sexual activities. The rest use at times or never used condoms at all placing themselves at higher risk of HPV infection. To add to this, a significant $19.5 \%$ of the sexually active participants had more than one sexual partner again increasing chances of HPV infection. Positive practice towards HPV prevention was further assessed by the uptake of Pap smear, of which only $25 \%$ had conducted the test reflecting a very low uptake and practice. Generally, the participants' practice regarding HPV and associated diseases was poor in this study. Whilst participants exhibited good knowledge and attitude, this was not entirely reflected in their practice.

\section{Conclusion}

There was moderate to high level of awareness regarding HPV, HPV vaccine and related diseases in this study. The majority of participants were aware of HPV, its vaccine, cervical cancer and Pap smear consistent with the nature of their academic studies. There was however low to average level of knowledge on specific aspects related to HPV, its vaccine and cervical cancer. Attitude of the participants were predominantly positive as attested by the participants ability to perceive risk and willingness to partake in vaccination programs and seek more knowledge on HPV. However there was an indication of poor practice related to HPV infection among the participants reflecting lack of translation of knowledge into beneficial practice by most of the participants. There is need for awareness campaigns to encourage female students to engage safe sexual practices that ensure prevention and reduce risk of HPV infection.

\section{ACKNOWLEDGEMENTS}

We are grateful to all the participants who kindly agreed to participate in our survey. No funding was received for the study.

\section{CONFlicts OF INTEREST Disclosure}

None declared.

\section{REFERENCES}

[1] Cancer Research UK: About cancer [Internet]. London: Cancer Research UK; What is HPV; 2 Septem- ber 2016 [cited 10 March 2017]. Available from: http: //www. cancerresearchuk.org/about-cancer/cancers-i $\mathrm{n}$-general/cancer-questions/what-is-the-hpv-virus 
[2] Centres for Disease Control and Prevention: HPV [Internet]. Atlanta USA: CDC; Genital HPV Infection - Fact Sheet; 16 November 2016 [cited 10 March 2017]. Available from: https://www.cdc.gov/ std/hpv/stdfact-hpv.html

[3] World Health Organisation [Internet]. Geneva: WHO Human Papilloma Virus (HPV) and Cervical Cancer; 15 February 2018 [cited 11 March 2018]. Available from: www . who.int/mediacentre/fact sheets/fs380/en

[4] Shetty N, Tang JW, Andrews J. Infectious disease: pathogenesis, prevention, and case studies. 1st ed. South gate, Chichester, West Sussex, United Kingdom: Wiley-Blackwell; 2009.

[5] Munoz K, Shroff N, Brown B. Reducing HPV Transmission in Developing Countries: The Importance of Education and the Necessary Vaccinations. Journal of Global Health Perspectives. 2012 Nov 18 [cited 20 March 2017]. Available from: http://www.jglobalhealth.org/article/reducing-hpv -transmission-in-developing-countries-the-importa nce-of-education-and-the-necessary-vaccinations-2/

[6] Winer RL, Lee SK, Hughes JP, et al. Genital human Papillomavirus infection: incidence and risk factors in a cohort of female university students. American Journal of Epidemiology. 2003; 157(9): 218-226. PMid:12543621. https://doi.org/10.1093/aje/kwf 180

[7] Makwe CC, Anorlu RI, Odeyemi KA. Human papillomavirus (HPV) infection and vaccines: knowledge, attitude and perception among female students at the University of Lagos, Lagos, Nigeria. Journal of Epidemiology and Global Health. 2012; 2: 199-206. PMid:23856501. https://doi.org/10.1016/j.jegh.2012.11.001

[8] The World Bank Data [Internet]. Washington DC: World Bank Open Data - Namibia; 2016 [Cited 20 March 2017]. Available from: http://data. worldbank.org/country/namibia

[9] HPV centre: Barcelona-Spain: Namibia - Human Papillonavirus and Related Cancers - Fact sheet 2017. 27 July 2017 [cited 5 March 2018]. Available from: http://www.hpvcentre.net/statisti cs/reports/NAM_FS.pdf

[10] Bloch B, Homer L, Orford HJ, et al. High risk factors for cervical cancer: An epidemiological study in SWA/Namibia. South African Medical Journal. 1988; 74(6): 284-289. PMid:2843990.

[11] Report on needs assessment: Screening for Reproductive System Cancers. Ministry Of Health and Social Services Namibia. 2011. Windhoek, Namibia: John Meinert printing.
[12] Chikandiwa AT. Awareness, knowledge and attitudes towards Human Papilloma virus among female tertiary students in South Africa .2010; Masters Thesis, University of Western Cape, Western Cape, South Africa. Available from: http://etd.uwc.ac.za/xmlui/bitstream/handle/11394 /2114/Chikandiwa_MPH_2010.pdf?sequence=1

[13] Wong LP, Sam I. Ethnically diverse female university student's knowledge towards human Papillomavirus (HPV), HPV vaccination and cervical cancer. European Journal of Obstetrics and Gynaecology and Reproductive Biology. 2009; 148(2010): 90-95. PMid:19910102. https://doi.org/10.1016/j.ejogrb.2009.10.002

[14] Lopez RV, Tanjasiri SP, McMahan S. College aged men (18-24) knowledge and perceptions of Human Papillomavirus and cervical cancer. California Journal of Health Promotion. 2008; 6(1): 143-155.

[15] Uzunlar O, Ozyer S, Baser E, et al. A survey on Human Papillomavirus awareness and acceptance of vaccination among nursing students in tertiary hospital in Ankara Turkey. Vaccine. 2013; 17: 2191-5. PMid:23375980. https://doi.org/10.1016/j.vaccin e.2013.01.033

[16] Tahir MK, Malik AB, Inayat UR, et al. Knowledge, attitudes, and perception towards human papillomavirus among university students in Pakistan. Papillomavirus Research. 2016; 2: 122-127.

[17] Tripathy S, Mohapatra S, Muthulakshmi M, et al. Knowledge, attitude towards human papillomavirus and HPV vaccine among medical students of a tertiary care teaching hospital in India. Int J Reprod Contracept Obstet Gynecol. 2015; 4(6): 1771-1774. https : //doi.org/10.18203/2320-1770.ijrcog20150926

[18] Phianmongkhol Y, Suwan N, Srisomboon J, et al. Knowledge about human papillomavirus infection and cervical cancer prevention among nurses in Chiang Mai University Hospital, Thailand. Asian Pacific J Cancer Prev. 2011; 12: 823-825. PMid:21627391.

[19] Maharajan MK, Rajiah K, Num KS, et al. Knowledge of Human Papillomavirus Infection, Cervical Cancer and Willingness to pay for Cervical Cancer Vaccination among Ethnically Diverse Medical Students in Malaysia. Asian Pac J Cancer Pre. 2015; 16(14): 5733-9. https://doi.org/10.7314/APJCP.2015.16.14.5733

[20] Makwe CC, Anorlu RI. Knowledge and attitude towards human Papillomavirus infection and vaccines among female nurses at a tertiary hospital in Nigeria. International Journal of Women's Health. 2011; 3: 313-317. PMid:21976985. https ://doi .org/10.2147/IJWH .S22792 